\title{
YOU'VE IMPROVED THE PROCESS, BUT DO YOU KNOW HOW MUCH YOU'VE SAVED THE NHS?
}

\author{
C Asher \\ Finance Manager \\ University Hospitals Coventry and Warwickshire
}

The NHS is a rich tapestry of professionals from all walks of life, dedicating their working lives to serving the UK population's health needs. Everyday there are individuals seeking to make a positive difference, for their patients, for their teams and for their students. Throw in Brexit or even a pandemic, and the cogs just keep turning.

Initially qualifying as a Chartered Accountant with the National Audit Office, I saw the NHS as a huge set of consolidated accounts fed into by an overwhelming number of sources. For someone who spent several years undertaking substantive testing at various NHS bodies - I had a phenomenally poor understanding of its financial inner workings and values. Leaving the financial world behind, I sought to serve society by studying medicine. It has been a hell of a journey but seeing the passion, dedication and pride exuded by those working in a hospital (clinical and non-clinical) has been nothing short of awe-inspiring. Sure, it's a job and it pays the bills. However, there's far more than the pay cheque that draws its employees to give everything they can to ensure every patient is treated with respect and dignity. I have spent the past four years understanding the clinical aspects of the NHS. How various services feed into each other, following the patient journey and building knowledge of a doctors' responsibilities are just a few of the things I've learned being on "the other side".

Many finance colleagues will agree, you never really escape. I started to reflect on my experiences both clinically and financially and found that the analytical skills I had gained in accountancy were very relevant to those required of a doctor. Though many clinicians may not realise it, they are making financial decisions every day; deciding on appropriate imaging based on cost, prescribing generic drugs vs branded ones, for example. I wanted to find a way of combining these two significant aspects of my professional experience to help drive improvement both in terms of quality and value for money. This is where the familiar term 'audit' came into play.

Clinical audits form a significant part of a clinician's workload and are very different from the external and internal audits I worked on as a Chartered Accountant. I was, embarrassingly, excited to undertake audits as it was such familiar territory for me and I understood its importance. The most useful outcome of these audits is the identification of a way to improve compliance with relevant guidelines by undertaking process improvements. In most cases, when a junior doctor is conducting this work, they are not thinking of how much money they're saving the NHS. They're focussed on improving patient care and meeting compliance indicators. 
I began to wonder whether there was a way of quantifying the process improvements financially, ideally promoting buy-in and encouraging others to consider the same.

As a result of COVID-19, a gap arose in the commercial finance team for an interim finance manager to help with the added workload. This was an incredible opportunity for me to learn how an NHS Trust financially works and tie it into my clinical knowledge. The team's Commercial Finance Manager, who was my line manager, is the embodiment of NHS values. She demonstrated strong leadership, dedication to supporting her colleagues and a stout advocate for equality and diversity. She was extremely supportive of my vision and gave me projects that would allow me to build an understanding of how the money mill worked. I was able to build a picture of what occurs clinically and financially during a patient's stay; from their initial presentation all the way through to discharge.

I gained an appreciation for clinical coding, and its complexity, by working on a project regarding profitability. The exposure to members of different teams gave me an opportunity to understand the challenges faced by individuals trying to optimise their roles in such a colossal system. A mixture of information systems that don't interface, overflowing inboxes and multi-user input means trying to build a comprehensive picture of a particular data aspect, such as costs, becomes overwhelmingly difficult. One can invest a substantial amount of time and effort into collating information; however, gaps always remain. Importantly, I found like-minded clinicians who had conducted their own projects to gain a similar understanding and improve the value that their teams could offer. Most inspiring was a Trauma \& Orthopaedics Consultant who developed an app to assist with clinical coding. They took the time to develop a detailed understanding of clinical coding and now the procedures that their team conducts are captured more accurately, attracting the most appropriate tariffs.

Thus far I have been involved in two pieces of work undertaken by clinicians. The first was to assess the outcomes of diverging from the pre-established animal hand bite protocol, where patients would no longer be kept overnight on IV antibiotics. The new process entails a thorough wash-out in ED upon presentation, discharge with oral antibiotics, followed by planned surgical washout in day theatres the following day. The newer protocol has resulted in reduced patient length of stay, improved patient experience and efficiency savings. Quantifying this was something they were very much hoping to do so I offered to contact the relevant individuals, obtain the data and produce the necessary analysis. The analysis showed that by applying the new protocol, efficiency savings were made in direct, indirect and overhead cost areas when calculated per patient. There was an average $89 \%$ saving in ward costs and a $58 \%$ reduction in length of stay. There were modest savings in pharmacy costs resulting from moving to oral antibiotics- though this move would more impact length of stay and ward costs due to mode of administration. Overall, the new protocol produced an average total cost saving of $40 \%$ compared to treating patients under the old protocol. Being able to support protocol amendments with sound monetary figures meant that the new protocol could be proven to be more efficient than the previous one.

The second piece of work is still on-going, looking at patient satisfaction and experience after moving from face-to-face clinics to virtual clinics as a result of the COVID-19 pandemic. Moving from payment by results to block payments has made comparing historical to current income data difficult, however, it has been a useful exercise in developing innovative ways to analyse the information available to identify where efficiencies have been made. The clinic and waiting areas have been utilised by other teams, senior clinicians have been freed up to undertake other activities and the number of non-attendees has dramatically fallen. It is my vision that all such studies would include some financial cost-benefit analyses to support process improvements, eventually establishing toolkits and pathways for clinicians to access the necessary financial data and assistance in analysing it.

I had the pleasure of joining the Finance for Clinicians virtual event in January 2021. I found the presentations fascinating and was especially excited by the prospect of a new user interface for PLICS. The coding workshop was extremely helpful, and I have taken away useful examples of how important language written by clinicians is for correct coding and what a difference

"THE EXPOSURE TO MEMBERS OF DFFERENT TEAMS GAVE ME AN OPPORTUNITY TO UNDERSTAND THE CHALLENGESFACED BY INDIVIDUALS TRYING TOOPTIMISE THEIR ROLES IN SUCH A COLOSSAL SYSTEM." 
it can make in terms of earning the appropriate tariff. I hope to communicate these messages to colleagues and gradually improve the terminology we use in our notes and when we discharge patients.

As I embark upon the first rung of the junior doctor ladder, I hope to undertake more projects to help clinicians understand and utilise financial analyses. I aspire to produce toolkits and run workshops on how to obtain the desired data in a format in which effective analyses can be undertaken. I want to contribute to the mission of developing financially astute clinicians to create an excellent service for our patients and a sustainable NHS for generations to come. Wish me luck!

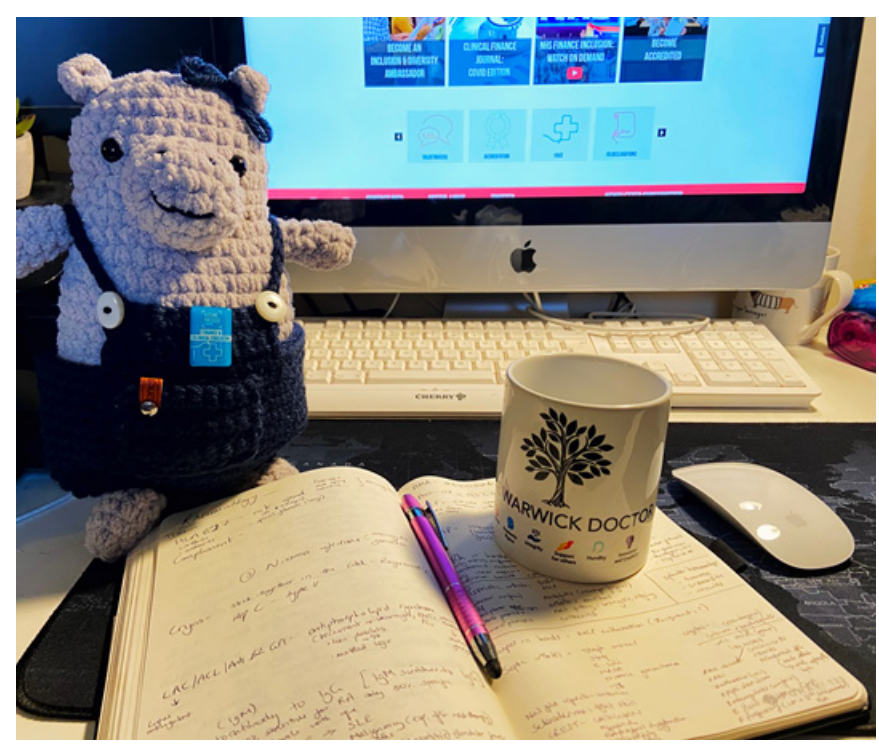

